\title{
Intrinsic Viscosity and Molecular Parameters of Wheat Starch-Cress Seed Gum-Sucrose Mixture
}

\author{
Shokufeh Taziki Shams-Abadi ${ }^{1 \mathbb{D}}$, Seyed Mohammad Ali Razavi ${ }^{1, *}{ }^{\mathbb{D}}$, Mahdi Irani ${ }^{1(\mathbb{D})}$ \\ 1 Food Hydrocolloids Research Center, Department of Food Science and Technology, Ferdowsi University of Mashhad, PO \\ Box: 91775-1163, Mashhad, Iran \\ * Correspondence: s.razavi@um.ac.ir;
}

Scopus Author ID 14058852900

Received: 1.12.2020; Revised: 29.12.2020; Accepted: 30.12.2020; Published: 2.01.2021

\begin{abstract}
This study aimed to determine the effect of different substitution levels of cress seed gum (CSG, $0-15 \%$ ) and sucrose (SUC, $0-10 \%$ ) on the dilute solution properties of native wheat starch (NWS) in terms of intrinsic viscosity, Huggins constant, power-law model slope, berry number, master curve slope, critical concentration, shape factor, and swollen specific volume. In the presence of CSG, the intrinsic viscosity of NWS increased from 0.686 to $0.760 \mathrm{dl} / \mathrm{g}$, the molecular conformation changed from random coil to rod-like, the specific swollen volume enhanced from 0.27 to $0.32 \mathrm{dl} / \mathrm{g}$ and the shape factor altered from spherical to prolate. In contrast, sucrose reduced the intrinsic viscosity of NWS to $0.379 \mathrm{dl} / \mathrm{g}$ and the specific swollen volume to $0.15 \mathrm{dl} / \mathrm{g}$, altered the conformation to a more random coil and the shape factor to a more compact sphere. In the ternary system, the parameters were close to those of the starch-gum mixture. It can be concluded that CSG overcame the weakening effect of SUC on the NWS solution properties in the ternary system.
\end{abstract}

Keywords: biopolymer; conformation; sugar; starch; viscosity.

(C) 2020 by the authors. This article is an open-access article distributed under the terms and conditions of the Creative Commons Attribution (CC BY) license (https://creativecommons.org/licenses/by/4.0/).

\section{Introduction}

Native wheat starch (NWS) is a vital and low-cost source of starch in the world, which has shown numerous applications in the food industry [1] and textile, pharmaceutical, cosmetics, and paper industries [2,3] because of its interesting functional properties like thickening, filling, binding, gelling and stabilizing but these valuable properties are affected mainly by temperature, $\mathrm{pH}$ and shear force during processing, distribution, and storage. Therefore, manufacturers face some limitations, which may be improved by using hydrocolloids due to their unique physicochemical and functional properties [4].

Cress seed gum (CSG), as an emerging natural hydrocolloid, is a galactomannan with a mannose ratio to galactose of 8.2 and contains carbohydrates with hydroxyl carboxyl groups [5]. It has interesting physicochemical properties such as high molecular weight, high intrinsic viscosity, semi-rigid chain conformation, which causes macromolecular entanglement [6,7], and strong thickening/stabilizing behavior [5]. Concerning its functional properties (such as rheological, emulsifying, and foaming properties), CSG is not only heat stable under the thermal treatments used during processing, but these properties also improve after heat treatment [8].

Sugars are common additives used in the formulation of food products such as desserts (puddings, custard, crème caramel, etc.) and jellies and also pharmaceutical products as an economical, easy to process, bulking. A good tasting substance to mask the medicines' acrid 
taste and make them palatable and acceptable by children. The functionality and the behavior of biopolymers and co-solutes in the system can be related to individual polysaccharides' properties in the dilute solution domain. In a dilute solution, single polysaccharide coils are completely apart, and the chains do not overlap. Intrinsic viscosity, [ $\eta$ ], is an important property for studying biopolymers' features in dilute solutions. It is defined as the hydrodynamic volume occupied by an individual polymer molecule affected by the macromolecular chain conformation and solvent properties [9]. Sucrose (SUC) reduces the intrinsic viscosity of the NWS due to its ability to change the solvent properties. In this regard, it has been reported that the intrinsic viscosity of NWS decreased by about $6 \%$ due to adding $10 \%$ SUC [10]. It can be stated that the interactions between starch chains and solvent molecules decrease in the presence of SUC. Therefore, the volume of solvated molecules of the starch polymer decreases. SUC could boost the random coil conformation of NWS. As a result, it alters starch polymer chains' shape factor to a more compact sphere shape [10]. Besides, low concentrations of SUC reduce the intrinsic viscosity of CSG. In the presence of $10 \%$ SUC, the intrinsic viscosity of CSG decreases by about 3\% [6]. In the presence of SUC, the gum molecular conformation changes slightly from the conformation between the random coil and rigid rod to the random coil [6]. Also, the intrinsic viscosity of individual xanthan and guar gum reduces in the presence of SUC [11].

CSG has higher intrinsic viscosity compared to the NWS. The value of intrinsic viscosity has been estimated to be $3.916 \mathrm{dl} / \mathrm{g}$ for CSG [6] and about $1.685 \mathrm{dl} / \mathrm{g}$ for NWS $[10,13]$. A polymer with a higher intrinsic viscosity, like CSG, can affect the properties of wheat starch in dilute solution and control the starch-gum mixture's intrinsic viscosity $[14,15]$. Although the intrinsic viscosity of xanthan or guar gum reduces in the presence of SUC, because of the synergistic interactions between these hydrocolloids, the intrinsic viscosity of xanthan/guar mixture increases in the presence of 10 and 20\% SUC [11]. Therefore, the objectives of this research were to study the properties of NWS macromolecules in the presence of CSG $(0,5,10$, and $15 \%)$ and SUC $(0,5$, and $10 \%)$ in the dilute domain and characterize the properties of the ternary system of NWS-CSG-SUC.

\section{Materials and Methods}

\subsection{Materials.}

Cress seeds were purchased from a traditional medicine market in Mashhad, Iran. The cress seed gum powder (CSG) was produced following the method used by Karazhiyan et al. [15]. Native wheat starch (NWS) and reagent grade of sucrose (SUC) were purchased from Sigma Aldrich (St. Louis, Mo, USA) and Merck (Germany) Company, respectively.

\subsection{Samples preparation.}

NWS dispersions in deionized water $(1 \mathrm{~g} / \mathrm{dl})$ were prepared by addition of CSG and SUC at different levels of substitution $(0,5,10,15 \%$, and $0,5,10 \%$, respectively). At first, the CSG dispersion with/without SUC was stirred with a magnetic stirrer for $1 \mathrm{~h}$ at ambient temperature $\left(25^{\circ} \mathrm{C}\right)$. The dispersions were placed on a roller mixer for $24 \mathrm{~h}$ to complete the hydration. Then, the NWS powder was added, and the dispersions were stirred for $30 \mathrm{~min}$. To complete the solubilization of starch molecules, dispersions were loaded to autoclave $\left(121^{\circ} \mathrm{C}\right)$ for $1 \mathrm{~h}$. Finally, the prepared samples were centrifuged at $2500 \mathrm{~g}$ for $25 \mathrm{~min}$ after cooling to ambient temperature. 


\subsection{Determination of intrinsic viscosity.}

The viscosity of the dispersions $(\eta)$ and the solvent $\left(\eta_{s_{s}}\right.$ deionized water) was determined in triplicates at $25 \pm 0.1{ }^{\circ} \mathrm{C}$ in a thermostatic water bath, using an Ubbelohde capillary viscometer (Cannon Instrument, USA; capillary tube No. 100, K=0.019908 $\mathrm{mm}^{2} / \mathrm{s}^{2}$ ). The flow times of the solvent $\left(t_{s}\right)$ and the samples $(t)$ were recorded. Then, the relative and specific viscosities ( $\eta_{\text {rel }}$ and $\eta_{\text {sp }}$ ) were calculated using Eqns. (1) and (2), respectively:

$$
\begin{gathered}
\eta_{\text {rel }}=\eta / \eta_{s}=t / t_{s} \\
\eta_{s p}=\eta-\eta_{s} / \eta_{\mathrm{s}}=\eta_{\text {rel }}-1
\end{gathered}
$$

The intrinsic viscosity, $[\eta]$, was estimated by two procedures as follows:

1) The extrapolation method, according to the Huggins equation [16] (Eq. 3) and Kraemer equation [16] (Eq. 4):

$$
\begin{gathered}
\eta_{\mathrm{sp}} / \mathrm{c}=[\eta]+\mathrm{k}_{\mathrm{H}}[\eta]^{2} \mathrm{c} \\
\ln \eta_{\mathrm{rel}} / \mathrm{c}=[\eta]+\mathrm{k}_{\mathrm{k}}[\eta]^{2} \mathrm{c}
\end{gathered}
$$

Where $\mathrm{K}_{\mathrm{H}}$ and $\mathrm{K}_{\mathrm{K}}$ are the constants of the Huggins and Kraemer models, respectively.

2) The slope method, according to the three following models:

Tanglertpaibul-Rao's equation [18]:

$$
\eta_{\text {rel }}=1+[\eta] \mathrm{c}
$$

Higiro 1's equation [13]:

$$
\eta_{\text {rel }}=\mathrm{e}^{[\eta] c}
$$

Higiro 2's equation [13]:

$$
\eta_{\text {rel }}=1 / 1-[\eta] c
$$

\subsection{Estimation of molecular conformation.}

The power-law equation (Eq. 8) was used to estimate the molecular conformation of polysaccharides. In this equation, the $\mathrm{b}$ parameter values were determined by the slope of $\mathrm{a}$ double logarithmic plot of $\eta_{\mathrm{sp}}$ vs. C to obtain the molecular conformation [19].

$$
\eta_{\mathrm{sp}}=\mathrm{aC}^{\mathrm{b}}
$$

\subsection{Determination of coil-overlap parameters.}

Three parameters, including Berry number, the master curve slope, and the critical concentration, were used to investigate the polymers' chains' overlapping. The $\log \left(\eta_{\mathrm{sp}}\right)-$ $\log C[\eta]$ plot is known as "master curve", which was used to estimate the master curve slope (MCS). The Berry number, $\mathrm{C}[\eta]$, is a dimensionless parameter representing the polymer molecule's volume in the solution. The transition from the dilute domain to the concentrated domain, is called the critical concentration $\left(\mathrm{C}^{*}\right)$, which was calculated by the following equation $[21,10,13]$ :

$$
\mathrm{C}^{*}=2.5 / \eta
$$

\subsection{Estimation of shape factor and voluminosity.}

The voluminosity or the volume of a solvated polymer molecule $\left(v_{s}\right)$ was measured by plotting Y vs. concentration (C). Y value was calculated according to Eq. (10) [21]: 


$$
Y=\frac{\eta_{\text {rel }}^{0.5}-1}{\left[C\left(1.35 \eta_{\text {rel }}^{0.5}-0.1\right)\right]}
$$

Another factor for the study of the biopolymer characteristics is the shape factor (v), which expresses the macromolecular shape in the solution. The shape factor was determined by Eq. (11) [21]:

$$
[\eta]=v \times v_{s}
$$

\subsection{Statistical analysis.}

In this study, the effect of sucrose and cress seed gum addition at different levels of substitution $((0,5$ and $10 \%)$ and $(0,5,10$ and 15\%), respectively) on the characteristics of native wheat starch was investigated using a completely randomized design in a factorial arrangement. All data were estimated at least in duplicate. Experimental data were analyzed by one-way analysis of variance (ANOVA) at a statistical level of 5\%, and significant differences among means were determined by the Tukey test using Minitab statistical software (version 17). Excel software was used for drawing diagrams and fitting the rheological models.

\section{Results and Discussion}

\subsection{Intrinsic viscosity.}

The intrinsic viscosity, known as limiting viscosity number, is a good indicator of the hydrodynamic volume occupied by a single polymer molecule. This is experimentally determined by comparing solvent viscosity with soluble viscosity in a wide range of low concentrations [21]. The intrinsic viscosity [ 1 ] of NWS-SUC-CSG systems, determined by extrapolation and slope-based methods, are shown in Tables 1 and 2, respectively. It can be seen that Huggins, Tanglertpaibul-Rao, and Higiro's models showed high efficiency to determine the intrinsic viscosity. However, the data did not follow the Kraemer model. The results were similar to those reported by McMillan [22], and Behrouzian et al. [6], who found the intrinsic viscosity determined based on the slope of the plot (Tanglertpaibul-Rao and Higiro equations) had higher correlation coefficients and lower standard error than those obtained by the intercept (Huggins and Kraemer). The Higiro 1 model was selected as the best model, which indicated the highest values of the determination coefficient $\left(\mathrm{R}^{2}\right)$ and the lowest values of root mean square error (RSME) (Table 2). According to this model, the intrinsic viscosity of NWS was $0.686 \mathrm{dl} / \mathrm{g}$ at $25^{\circ} \mathrm{C}$. Heydari et al. [10], Irani et al. [12], and Funami et al. [23] estimated the intrinsic viscosity of NWS, in DMSO solution, at $25^{\circ} \mathrm{C}$ about $1.69 \mathrm{dl} / \mathrm{g}, 1.67 \mathrm{dl} / \mathrm{g}$, and 1.50 $\mathrm{dl} / \mathrm{g}$, respectively. It was reported that the value of the intrinsic viscosity of starch was higher in DMSO solvent. The reason behind this observation may be related to the high solubility of starch macromolecules in this solvent rather than other solvents such as potassium hydroxide $(1 \mathrm{~N})$, deionized water, sodium chloride, calcium chloride, and potassium hydroxide (1M) [24]. The thermal processing (the autoclave process) used in this study for better solubility of NWS in deionized water, degraded some parts of the amylose molecules and reduced their molecular weight and thereby reduced the intrinsic viscosity of the starch macromolecules [25].

The [ $\eta$ ] of NWS increased from $0.686 \mathrm{dl} / \mathrm{g}$ to $0.760 \mathrm{dl} / \mathrm{g}$ with increasing the CSG substitution level from $0 \%$ to $15 \%$, but it was significant just in $15 \%$ CSG substitution (Table 2), which caused about $10.79 \%$ increment in [ $\eta$ of NWS. 
Table 1. Intrinsic viscosity ([ๆ], dl/g) values calculated by the Huggins' model (Eq. 3) for native wheat starch (NWS) solution in the presence of cress seed gum (CGS) and sucrose (SUC) at different levels of substitution and constant temperature $\left(25^{\circ} \mathrm{C}\right)$.

\begin{tabular}{l|c|c|c|c}
\multirow{2}{*}{ CSG (\%) } & \multirow{2}{*}{ Parameters } & \multicolumn{3}{|c}{ SUC $(\%)$} \\
\cline { 3 - 5 } & & 0 & 5 & 10 \\
\hline 0 & {$[\eta]$} & $0.637 \pm 0.062^{\mathrm{cd}}$ & $0.454 \pm 0.006^{\mathrm{f}}$ & $0.363 \pm 0.009^{\mathrm{g}}$ \\
\hline & $\mathrm{R}^{2}$ & 0.970 & 0.981 & 0.933 \\
\hline 5 & RMSE & 0.004 & 0.002 & 0.004 \\
\hline & {$[\eta]$} & $0.658 \pm 0.046^{\mathrm{cd}}$ & $0.537 \pm 0.002^{\mathrm{e}}$ & $0.470 \pm 0.004^{\mathrm{f}}$ \\
\hline & $\mathrm{R}^{2}$ & 0.951 & 0.809 & 0.922 \\
\hline 10 & $\mathrm{RMSE}$ & 0.004 & 0.005 & 0.003 \\
\hline & {$[\eta]$} & $0.763 \pm 0.006^{\mathrm{b}}$ & $0.711 \pm 0.010^{\mathrm{bc}}$ & $0.626 \pm 0.008^{\mathrm{d}}$ \\
\hline 15 & $\mathrm{R}^{2}$ & 0.738 & 0.880 & 0.761 \\
\hline & $\mathrm{RMSE}$ & 0.011 & 0.008 & 0.011 \\
\hline & {$[\eta]$} & $0.849 \pm 0.012^{\mathrm{a}}$ & $0.725 \pm 0.002^{\mathrm{bc}}$ & $0.687 \pm 0.008^{\mathrm{cd}}$ \\
\hline & $\mathrm{R}^{2}$ & 0.910 & 0.978 & 0.897 \\
\hline & RMSE & 0.007 & 0.003 & 0.006
\end{tabular}

All data are expressed as mean \pm standard deviation of three determinations. The same letters indicate no significant effect according to the Tukey test $(\mathrm{p}<0.05)$.

Table 1. Intrinsic viscosity (dl/g) values determined for native wheat starch (NWS) with the addition of cress seed gum (CSG) and sucrose (SUC) at different levels of substitution and constant temperature $\left(25^{\circ} \mathrm{C}\right)$.

\begin{tabular}{|c|c|c|c|c|c|}
\hline \multirow[t]{2}{*}{ Models } & \multirow[t]{2}{*}{ CSG (\%) } & \multirow[t]{2}{*}{ Parameters } & & SUC (\%) & \\
\hline & & & 0 & 5 & 10 \\
\hline \multirow[t]{12}{*}{ Tanglertpaibul-Rao } & \multirow[t]{3}{*}{0} & {$[\eta]$} & $0.847 \pm 0.004^{\mathrm{b}}$ & $0.547 \pm 0.001^{\mathrm{d}}$ & $0.451 \pm 0.001^{\mathrm{e}}$ \\
\hline & & $\mathrm{R}^{2}$ & 0.965 & 0.980 & 0.972 \\
\hline & & RMSE & 0.018 & 0.012 & 0.012 \\
\hline & \multirow[t]{3}{*}{5} & {$[\eta]$} & $0.785 \pm 0.092^{\mathrm{bc}}$ & $0.608 \pm 0.001^{\mathrm{d}}$ & $0.538 \pm 0.000^{\mathrm{d}}$ \\
\hline & & $\mathrm{R}^{2}$ & 0.981 & 0.987 & 0.985 \\
\hline & & RMSE & 0.010 & 0.007 & 0.006 \\
\hline & \multirow[t]{3}{*}{10} & {$[\eta]$} & $0.861 \pm 0.002^{\mathrm{b}}$ & $0.829 \pm 0.001^{\mathrm{b}}$ & $0.745 \pm 0.001^{\mathrm{c}}$ \\
\hline & & $\mathrm{R}^{2}$ & 0.985 & 0.984 & 0.976 \\
\hline & & RMSE & 0.012 & 0.011 & 0.013 \\
\hline & \multirow[t]{3}{*}{15} & {$[\eta]$} & $0.976 \pm 0.003^{\mathrm{a}}$ & $0.816 \pm 0.003^{b c}$ & $0.791 \pm 0.002^{\mathrm{bc}}$ \\
\hline & & $\mathrm{R}^{2}$ & 0.986 & 0.992 & 0.986 \\
\hline & & RMSE & 0.015 & 0.010 & 0.011 \\
\hline \multirow[t]{12}{*}{ Higiro 1} & \multirow[t]{3}{*}{0} & {$[\eta]$} & $0.686 \pm 0.003^{b c}$ & $0.453 \pm 0.001^{\mathrm{f}}$ & $0.379 \pm 0.001^{\mathrm{g}}$ \\
\hline & & $\mathrm{R}^{2}$ & 0.997 & 0.999 & 0.997 \\
\hline & & RMSE & 0.004 & 0.002 & 0.002 \\
\hline & \multirow[t]{3}{*}{5} & {$[\eta]$} & $0.657 \pm 0.068^{\mathrm{bcd}}$ & $0.515 \pm 0.001^{\mathrm{e}}$ & $0.461 \pm 0.000^{\mathrm{ef}}$ \\
\hline & & $\mathrm{R}^{2}$ & 0.998 & 0.995 & 0.998 \\
\hline & & RMSE & 0.002 & 0.003 & 0.001 \\
\hline & \multirow[t]{3}{*}{10} & {$[\eta]$} & $0.709 \pm 0.001^{\mathrm{ab}}$ & $0.689 \pm 0.001^{\mathrm{bc}}$ & $0.618 \pm 0.001^{\mathrm{d}}$ \\
\hline & & $\mathrm{R}^{2}$ & 0.994 & 0.997 & 0.994 \\
\hline & & RMSE & 0.005 & 0.003 & 0.004 \\
\hline & \multirow[t]{3}{*}{15} & {$[\eta]$} & $0.760 \pm 0.002^{\mathrm{a}}$ & $0.656 \pm 0.002^{\text {bcd }}$ & $0.649 \pm 0.001^{\mathrm{cd}}$ \\
\hline & & $\mathrm{R}^{2}$ & 0.988 & 0.991 & 0.995 \\
\hline & & RMSE & 0.008 & 0.008 & 0.005 \\
\hline \multirow[t]{12}{*}{ Higiro 2} & \multirow[t]{3}{*}{0} & {$[\eta]$} & $0.564 \pm 0.002^{\mathrm{abc}}$ & $0.381 \pm 0.001^{\mathrm{f}}$ & $0.322 \pm 0.001^{\mathrm{g}}$ \\
\hline & & $\mathrm{R}^{2}$ & 0.965 & 0.951 & 0.972 \\
\hline & & RMSE & 0.004 & 0.009 & 0.006 \\
\hline & \multirow[t]{3}{*}{5} & {$[\eta]$} & $0.556 \pm 0.050^{\text {bcd }}$ & $0.440 \pm 0.000^{\mathrm{e}}$ & $0.398 \pm 0.000^{\mathrm{ef}}$ \\
\hline & & $\mathrm{R}^{2}$ & 0.952 & 0.942 & 0.957 \\
\hline & & RMSE & 0.008 & 0.008 & 0.006 \\
\hline & \multirow[t]{3}{*}{10} & & $0.591 \pm 0.001^{\mathrm{ab}}$ & $0.579 \pm 0.001^{\mathrm{abc}}$ & $0.519 \pm 0.001^{\mathrm{d}}$ \\
\hline & & $\mathrm{R}^{2}$ & 0.924 & 0.947 & 0.949 \\
\hline & & RMSE & 0.013 & 0.010 & 0.009 \\
\hline & \multirow[t]{3}{*}{15} & {$[\eta]$} & $0.604 \pm 0.001^{\mathrm{a}}$ & $0.536 \pm 0.001^{\mathrm{cd}}$ & $0.540 \pm 0.001^{\mathrm{cd}}$ \\
\hline & & $\mathrm{R}^{2}$ & 0.844 & 0.889 & 0.922 \\
\hline & & RMSE & 0.019 & 0.017 & 0.013 \\
\hline
\end{tabular}

All data are expressed as mean \pm standard deviation of three determinations. The same letters indicate no significant effect according to the Tukey test $(\mathrm{p}<0.05)$. 
This result was attributed to the higher intrinsic viscosity of CSG in comparison to NWS. In this research, the intrinsic viscosity of CSG was estimated at $2.270 \mathrm{dl} / \mathrm{g}$. Khouryieh et al. [14] reported that the intrinsic viscosity of the mixture of xanthan/guar gum increased by adding xanthan $(\mathrm{XG})$ to the guar gum $(\mathrm{GG})$ solution due to their intermolecular bonding and higher intrinsic viscosity of XG rather than GG. Also, Higiro et al. [13] observed that the intrinsic viscosity of $60 \%$ xanthan $(\mathrm{XG})-40 \%$ locust bean gum (LBG) mixture was higher than the values of individual polymers, while the intrinsic viscosity of the mixture with $40 \%$ XG$60 \%$ LBG was slightly increased compared to each of them, confirming the intermolecular synergistic effect of XG and LBG. Their results also showed that increasing XG level in XGLBG mixture (XG with a higher intrinsic viscosity rather than $L B G$ ) led to more increment in the $[\eta]$ of the mixture.

The [ $\eta$ ] of NWS decreased noticeably (about 44.75\%) from $0.686 \mathrm{dl} / \mathrm{g}$ to $0.379 \mathrm{dl} / \mathrm{g}$ with increasing SUC substitution level from 0 to $10 \%$ (Table 2). As seen in Table 2, the 10\% substitution level of SUC was more effective in decreasing [n] than 5\% substitution $(44.75 \%$ reduction vs. $33.96 \%$ reduction). Similar observations have been obtained by Heydari et al. [10], who reported that the intrinsic viscosity of NWS decreased from $1.70 \mathrm{dl} / \mathrm{g}$ to $1.53 \mathrm{dl} / \mathrm{g}$ as the substitution level of SUC increased from 5 to $15 \%$. SUC reduces the solvent properties by decreasing the dielectric constant and reduces the accessibility of solvent molecules for the hydration of starch macromolecules. Thus, the conformation of starch molecules is less expanded. The hydrodynamic volume of molecules reduces, and accordingly, the intrinsic viscosity decreases [10]. Also, SUC may penetrate the amorphous region of starch molecules and compress them by forming bonds with them. It reduces the volume of hydration and decreases the intrinsic viscosity [26]. The competition between SUC and starch molecules for solvent increases as the sugar substitution level increases. As a result, fewer free-water molecules will remain intact with starch molecules and reduces hydrodynamic volume. Behrouzian et al. [6] reported that in a low concentration of SUC (up to 20\%), the intrinsic viscosity of the CSG decreased. A similar result has been observed by Mohammad Amini and Razavi [28], who found that the [n] of Balangu seed gum (BSG) decreased about $51.35 \%$ and $28.22 \%$ by adding $10 \%$ and $40 \%$ sugar, respectively. In another research done by Bak and Yoo [11], the intrinsic viscosity of XG and GG solution in the presence of SUC also declined to owe to the competition for water in the system and changing the conformation of the gums macromolecules. Also, Masselot et al. [27] reported that the intrinsic viscosity of hydroxypropylmethylcellulose and locust bean gum reduced in the presence of SUC.

The results showed that in the presence of CSG and SUC, CSG reduced the negative effect of SUC on the [ $\eta]$ reduction of NWS. The effect of CSG on the [ $\eta]$ of the NWS-CSGSUC mixture was more pronounced with increasing concentration of CSG. In this regard, the $[\eta]$ reduction of NWS in the presence of 5 and 10\% SUC substitution was 33.96 and $44.75 \%$, but in the presence of 5\% and 15\% CSG substitution, these values decreased about 24.93$32.80 \%$ and $4.37-5.39 \%$, respectively. Similar observations have been reported by Bak and Yoo [11]. They found the intrinsic viscosity values of the binary mixture of XG and GG in the presence of SUC were more than those of the individual XG-SUC and GG-SUC mixtures. It is possible that XG and GG interacted with each other and increased the viscosity of the mixture. Additionally, XG with higher intrinsic viscosity plays an important role in increasing the mixture's intrinsic viscosity, so it can control the [ $\eta]$ of the mixture. Another reason would be related to the balance that occurred between water and SUC in the system, which provides conditions for the interaction of gums with each other. 


\subsection{Huggins constant.}

Huggins constant $\left(k_{H}\right)$ is a momentous parameter to determine the hydrodynamic interactions between polymer-polymer and solvent-polymer in the dilute domain and determine the quality of the solvent and shows the macromolecules aggregation. The $k_{H}$ value is affected by the structure and shape of the molecule and the polymer coils' expansion. The $k_{H}$ values of perfect solutions are in the range of 0.3-0.7 [29], whereas, for flexible macromolecules with expanded shapes in a suitable solvent, this parameter's magnitude is in the range 0.2-0.4 [29,30]. For poor solvent, Huggins constant is higher than 1, which would bolster the formation of aggregates [29]. Huggins's constant values of the samples are shown in Table 3. The $k_{H}$ for NWS in deionized water at $25^{\circ} \mathrm{C}$ was 0.53 , and it decreased 0.26 by increasing the gum substitution up to $15 \%$. There were no significant differences between CSG substitution levels ( $>0.0 .5$ ). The results indicated that the solvent was perfect for NWS and NWS-CSG mixture $\left(k_{H}<0.7\right)$, representing no aggregates formed in solution. It can be concluded that in the presence of CSG, polymer-solvent interactions are more desirable than polymer-polymer interactions. The results of Wang et al. [32] also showed that the $k_{H}$ of waxy corn starch reduced with increasing xanthan fraction in the starch-xanthan mixture. In contrast to the influence of gum substitution level on the $k_{H}$ value, the $k_{H}$ value increased with increasing the sugar concentration from 0.53 (as control) to 0.71 at the $10 \%$ SUC substitution level. The results revealed that although the SUC exists, although the solvent's quality decreased, no molecular entanglements occurred. Heydari et al. [10] reported that the $k_{H}$ value of NWS increased as the sugar concentration of starch solutions increased from $0 \%$ to $15 \%$. This observation was related to a decrease in solvent molecules' availability for dispersing the starch segments due to the competition between sugar and starch molecules for accessing solvent. Thus, the interactions between starch molecules increase while the starch-solvent interactions reduce [10]. Mohammad Amini and Razavi [28] also reported that sugars decrease the BSG-solvent interactions, increased the interactions between BSG molecules, and consequently increased the $k_{H}$ of the BSG solution.

Table 3. The values of Huggins constant $\left(\mathrm{k}_{\mathrm{H}}\right)$ of native wheat starch solution (NWS) as affected by the addition of cress seed gum (CSG) and sucrose (SUC) at different levels of substitution and constant temperature $\left(25^{\circ} \mathrm{C}\right)$.

\begin{tabular}{l|l|l|l}
\multirow{2}{*}{ CSG (\%) } & \multicolumn{3}{|l}{ SUC $(\%)$} \\
\cline { 2 - 4 } & 0 & 5 & 10 \\
\hline 0 & $0.53 \pm 0.10^{\mathrm{a}}$ & $0.57 \pm 0.07^{\mathrm{a}}$ & $0.71 \pm 0.09^{\mathrm{a}}$ \\
\hline 5 & $0.47 \pm 0.01^{\mathrm{a}}$ & $0.38 \pm 0.01^{\mathrm{a}}$ & $0.49 \pm 0.04^{\mathrm{a}}$ \\
\hline 10 & $0.33 \pm 0.01^{\mathrm{a}}$ & $0.47 \pm 0.02^{\mathrm{a}}$ & $0.49 \pm 0.01^{\mathrm{a}}$ \\
\hline 15 & $0.26 \pm 0.02^{\mathrm{a}}$ & $0.28 \pm 0.02^{\mathrm{a}}$ & $0.35 \pm 0.02^{\mathrm{a}}$
\end{tabular}

All data are expressed as mean \pm standard deviation of duplicate. The same letters indicate no significant effect according to the Tukey test $(\mathrm{p}<0.05)$.

As shown in Table 3, the $k_{H}$ values of NWS-CSG-SUC mixtures were all less than 0.71, suggesting no aggregation occurred in the NWS-CSG-SUC solutions. Besides, the $k_{H}$ value for the NWS-CSG-SUC mixture was lesser than that of the NWS and NWS-SUC mixture, while it was greater than that of the NWS-CSG mixture. The results showed that, in comparison with the NWS solution and the NWS-SUC mixture, more solvent-polymer interactions were observed in the NWS-CSG-SUC mixture. It can be related to the NWS and CSG synergistic effects [11], which reduced the negative effect of SUC on the $k_{H}$ increment of the NWS solution, especially at a high substitution level of CSG (15\% CSG). The results of $k_{H}$ changes as a function of either CSG or SUC's substitution levels, and both of them were in agreement with the results of the intrinsic viscosity. 


\subsection{Molecular conformation.}

In dilute solutions, the molecular conformation of polymers is determined by calculating the power-law model's slope, namely $b$ parameter (Eq. 8) . The slope ( $b$ parameter) greater than 1 indicates random coil conformation while the slope less than 1 is related to rodlike conformation [33]. The values of the $b$ parameter of the samples are shown in Fig. 1. This parameter for NWS was 1.20, indicating a random coil conformation. This result was in line with the results observed by Irani et al. [12] and Heydari et al. [10], who reported $b$ values of 1.49 and 1.23 for NWS, respectively. The little differences may be related to the solvent used for the preparation of the starch solution.

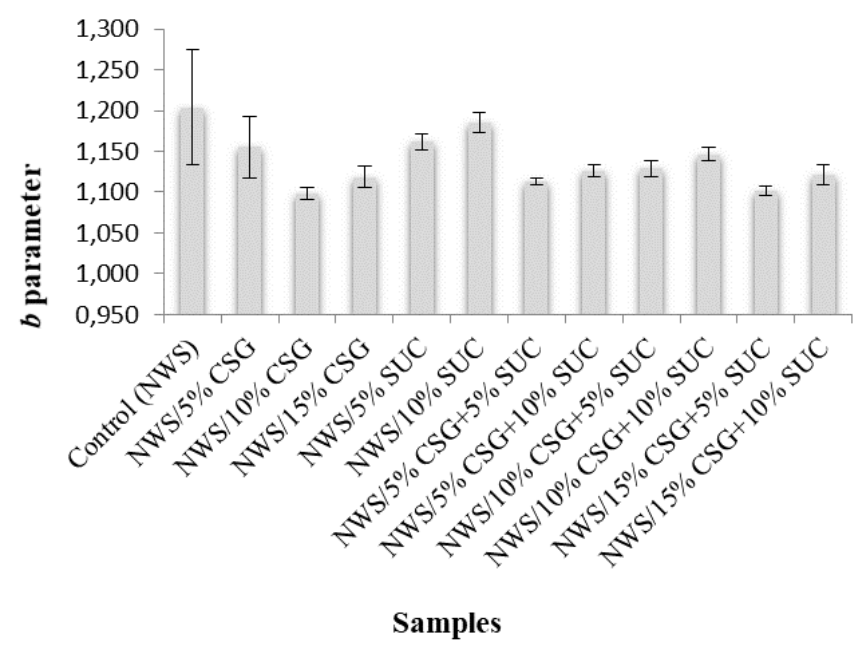

Figure 1. The values of the power equation slope ( $b$ parameter, Eq. (8)) determined for native wheat starch (NWS) with the addition of cress seed gum (CSG) and sucrose (SUC) at different levels of substitution and constant temperature $\left(25^{\circ} \mathrm{C}\right)$.

As seen in Fig. 1, by increasing the CSG substitution level from $0 \%$ to $15 \%$, the value of the $b$ parameter for NWS decreased from 1.20 to 1.12. Behrouzian et al. [6] estimated the value of 1.08 for the $b$ parameter of CSG, which is between random coil and rod-like conformations. It means that the macromolecular chain conformation of CSG is a semi-rigid [5,11]. As a result, in this study, the conformation of NWS-CSG mixture molecules changed from random coil toward rod-like due to CSG addition to the NWS solution. Similar results were obtained in another work in which the conformation of gums blend molecules changed from random coil to rod-like by adding xanthan gum (rod-like conformation) to the locust bean gum solution (random coil conformation) [13].

In this study, we found that $5 \%$ and $10 \%$ substitutions with SUC reduced the value of the $b$ parameter of NWS from 1.20 (the control sample) to 1.16 and 1.18 , respectively. In contrast, Heydari et al. [10] observed that the $b$ parameter of NWS increased from 1.22 to 1.32, with increasing the concentration of sugar from 0 to $15 \%$. Behrouzian et al. [6] also stated that increasing the SUC concentration increased the value of the $b$ parameter. Our observations showed that at selected SUC substitution levels, the molecular conformation of NWS was a random coil. This observation was in agreement with the result obtained by Heydari et al. [10].

According to the values of the $b$ parameter of the NWS-CSG-SUC mixtures, the lowest value was 1.10, related to the substitution levels of 15\% CSG and 5\% SUC (Fig. 1). It seems that the molecular conformation of the NWS-CSG-SUC complex has changed into the conformation between the random coil and rod-like. The results of the molecular conformation agreed with the results of intrinsic viscosity. In dilute solutions, the polymer chains are separate 
from each other, and the chains' dimensions affect the [ $\eta]$ of the polymer. The chains' dimensions of the polymer with a more rigid conformation increase further in water rather than polymers with a flexible random coil conformation; thus, it increases the [ $\eta$ ] value [14]. As mentioned earlier, CSG is more rigid than NWS, and thus, it has the ability to increase the viscosity of the NWS solution.

\subsection{Coil-overlap parameters.}

Master curve slope (MCS), Berry number $(\mathrm{C}[\eta])$ dimensionless, and critical concentration $\left(\mathrm{C}^{*}\right)$ parameters were determined as the coil-overlap parameters of NWS, NWSCSG, NWS-SUC, and NWS-CSG-SUC mixtures. MCS was estimated by the slope of the plot of $\log \left(\eta_{\text {sp }}\right)$ vs. $\log (\mathrm{C}[\eta])$. In the dilute domain, MCS is close to 1.4 , and in the concentrate domain, it increases to 3.3 [21]. In this study, the master curve slope values were obtained less than 1.4 for all the samples (Table 4), which shows that the samples were in the dilute domain, and no molecular entanglement occurred. According to Table 4, the MCS of NWS was 1.20. It decreased to 1.16-1.12, and 1.16-1.18 as the substitution levels of CSG and SUC increased, respectively. The CSG substitution effect on reducing the MCS of NWS was more effective than the SUC substitution. Heydari et al. [10] also found that with 5\% and 10\% substitutions of SUC, the MCS of the NWS solution had a decreasing trend. However, compared to the control, the sample with the 15\% SUC substitution level indicated a higher value of MCS. As shown in Table 4, the MCS of the NWS-CSG-SUC mixture was much lower than those of the NWS and NWS-SUC mixture in all substitution levels of CSG and SUC, which were in agreement with the results of intrinsic viscosity, $k_{H}$, and $b$ parameter.

Table 4. The values of Berry number $(\mathrm{C}[\eta])$, master curve slope (MCS), (slop of $\log \eta_{\mathrm{sp}}$ vs. $\left.\log \mathrm{C}[\eta]\right)$ and overlap concentration $\left(\mathrm{C}^{*}\right)$ determined for native wheat starch (NWS) with the addition of cress seed gum $(\mathrm{CSG})$ and sucrose (SUC) at different levels of substitution and constant temperature $\left(25^{\circ} \mathrm{C}\right)$.

\begin{tabular}{c|c|c|c|c} 
CSG (\%) & Parameters & \multicolumn{3}{|c}{ SUC (\%) } \\
\hline & & 0 & 5 & 10 \\
\hline 0 & $\mathrm{C}[\eta]$ & $0.29-0.47$ & $0.26-0.44$ & $0.25-0.41$ \\
\hline & $\mathrm{MCS}$ & $1.20 \pm 0.01^{\mathrm{a}}$ & $1.16 \pm 0.01^{\mathrm{a}}$ & $1.18 \pm 0.01^{\mathrm{a}}$ \\
\hline & $\mathrm{R}^{2}$ & 0.998 & 0.999 & 0.997 \\
\hline & $\mathrm{C}^{*}(\mathrm{~g} / \mathrm{dl})$ & $3.65^{\mathrm{ef}}$ & $5.51^{\mathrm{b}}$ & $6.60^{\mathrm{a}}$ \\
\hline 5 & $\mathrm{C}[\eta]$ & $0.26-0.42$ & $0.24-0.40$ & $0.24-0.36$ \\
\hline & $\mathrm{MCS}$ & $1.16 \pm 0.04^{\mathrm{a}}$ & $1.11 \pm 0.00^{\mathrm{a}}$ & $1.13 \pm 0.01^{\mathrm{a}}$ \\
\hline & $\mathrm{R}^{2}$ & 0.999 & 0.997 & 0.999 \\
\hline & $\mathrm{C}^{*}(\mathrm{~g} / \mathrm{dl})$ & $3.83^{\mathrm{def}}$ & $4.86^{\mathrm{c}}$ & $5.427^{\mathrm{b}}$ \\
\hline & $\mathrm{C} \eta \eta]$ & $0.25-0.47$ & $0.24-0.44$ & $0.25-0.44$ \\
\hline & $\mathrm{MCS}$ & $1.10 \pm 0.01^{\mathrm{a}}$ & $1.13 \pm 0.01^{\mathrm{a}}$ & $1.15 \pm 0.01^{\mathrm{a}}$ \\
\hline & $\mathrm{R}^{2}$ & 0.996 & 0.997 & 0.994 \\
\hline & $\mathrm{C}^{*}(\mathrm{~g} / \mathrm{dl})$ & $3.53^{\mathrm{fg}}$ & $3.63^{\mathrm{ef}}$ & $4.05^{\mathrm{d}}$ \\
\hline & $\mathrm{C}[\eta]$ & $0.33-0.59$ & $0.27-0.52$ & $0.26-0.47$ \\
\hline & $\mathrm{MCS}$ & $1.12 \pm 0.01^{\mathrm{a}}$ & $1.10 \pm 0.00^{\mathrm{a}}$ & $1.12 \pm 0.01^{\mathrm{a}}$ \\
\hline & $\mathrm{R}^{2}$ & 0.999 & 0.999 & 0.998 \\
\hline & $\mathrm{C}^{*}(\mathrm{~g} / \mathrm{dl})$ & $3.29^{\mathrm{g}}$ & $3.81^{\mathrm{def}}$ & $3.85^{\mathrm{df}}$
\end{tabular}

All data are expressed as mean \pm standard deviation of three determinations. The same letters indicate no significant effect according to the Tukey test $(\mathrm{p}<0.05)$.

The second dimensionless parameter was Berry number $(C[\eta]$, intrinsic viscosity $\times$ polymer concentration). Berry number more than 1 shows the molecular entanglements. As observed in Table 4, the Berry number for all samples was less than 1, meaning no coil overlap and molecular aggregation occurred. In this study, the Berry number of NWS was estimated in the range of 0.29-0.47. The increase in CSG substitution level (up to 15\%) increased this parameter to 0.33-0.59. An increase in the SUC substitution level (up to 10\%) decreased it to 
0.25-0.41. According to the results presented by Heydari et al. [10], the Berry number of wheat starch was in the range of $0.25-0.45$, but contrary to our study, they found that by increasing the concentration of SUC, the Berry number was increased to 0.26-0.47. In general, the results showed that in all the samples, even NWS-CSG-SUC mixtures, no coil overlap, and molecular entanglement occurred.

Critical concentration $\left(\mathrm{C}^{*}\right)$ reveals the overlap and onset of polymer entanglements. The concentrations lower than $\mathrm{C}^{*}$ is called the dilute domain, and the concentrations above $\mathrm{C}^{*}$ is known as the concentrated regime [21]. The $C^{*}$ values, calculated by Eq. (9), are shown in Table 4. The value of $\mathrm{C}^{*}$ was estimated as $3.64 \mathrm{~g} / \mathrm{dl}$ for NWS, followed by a significant decrease to $3.29 \mathrm{~g} / \mathrm{dl}$ with increasing the substitution levels of CSG up to $15 \%$. At the same time, it increased significantly to $6.60 \mathrm{~g} / \mathrm{dl}$ with increasing the SUC substitution level up to $10 \%$. Our observations were in agreement with the results of Wang et al. [32] and Islam et al. [26]. According to the results of Wang et al. [32], XG's addition lowered the $\mathrm{C}^{*}$ of the waxy corn starch-xanthan blend, which was affected by the ratio of XG. The results of Islam et al. [26] revealed that the $C^{*}$ of Sago starch significantly increased with increasing the glucose and SUC concentration. As shown in Table 4, the NWS-CSG-SUC mixture at selected substitution levels had higher $C^{*}$ values than the NWS and NWS-CSG mixture, but those were lower than the $C^{*}$ values of the NWS-SUC mixture. The overlap parameters are affected by the molecular conformation [30]. CSG has a semi-rigid chain conformation [9] that leads to more expansion of the water's molecular structure and tends to entangle at a lower concentration. But in the presence of SUC, the NWS structure was more compressed, so a higher concentration of starch was needed for molecular entanglements/overlap to occur in the system.

\subsection{Shape factor and swollen specific volume.}

Intrinsic viscosity is affected by molecular shape and swollen specific volume parameters. The molecular shape parameter (v) is known as viscosity increment [31]. If the shape factor ( $v$ ) value is equal to 2.5 , the polymer coils shape is spherical; for values more than 2.5 , it is an ellipsoidal shape. For particles of a different shape factor value, it is oblate or prolate [34]. According to the results presented in Table 5, the $v$ value of NWS was estimated as 2.54, showing the molecular shape of the NWS is spherical. With increasing the CSG substitution level from $0 \%$ to $15 \%$, the value of $v$ for NWS decreased from 2.54 to 2.33 . The results indicated that, in the presence of CSG, the shape of NWS changed from spherical to oblate or prolate, which can be due to the expanded conformation of the CSG polymer. The $v$ value of the NWS-SUC was reduced to 2.48 by $5 \%$ SUC substitution, but no change was observed with $10 \%$ SUC substitution compared to the sugar-free NWS solution (Table 5). These results revealed that in the presence of SUC, the shape of the particles was also sphere-like. However, the SUC addition resulted in a decrease in the expansion of NWS molecules and thus a change in shape toward a more compact sphere [10,28]. Mohammad Amin and Razavi [28] observed that the value of the shape factor of Balangu seed gum (BSG) reduced with increasing the concentration of SUC. While Heydari et al. [10] stated that the value of the NWS shape factor increased at $10 \%$ SUC and decreased at $15 \%$ SUC. As shown in Table 5, in the presence of both CSG and SUC, the value of $v$ of NWS-CSG-SUC decreased compared to the NWS, especially in the highest substitution level of CSG (15\%). The $v$ value of the NWS-CSG-SUC mixture was in the range of 2.34-2.45, indicating the particles' shapes were oblate or prolate. In general, it can be stated that by adding the CSG and SUC to the NWS solution, the effect of 
CSG can be overcome on the SUC, and it would prevent the increment of the shape factor value.

Table 5. Shape factor (v) and voluminosity ( $v_{\mathrm{s}}$ ) of native wheat starch (NWS) with the addition of cress seed gum (CSG) and sucrose (SUC) at different levels of substitution and constant temperature $\left(25^{\circ} \mathrm{C}\right)$.

\begin{tabular}{c|c|c|c|c} 
CSG (\%) & Parameters & \multicolumn{3}{|c}{ SUC (\%) } \\
\hline & & 0 & 5 & 10 \\
\hline 0 & $v(-)$ & $2.54 \pm 0.14^{\mathrm{a}}$ & $2.48 \pm 0.02^{\mathrm{a}}$ & $2.53 \pm 0.02^{\mathrm{a}}$ \\
\hline & $v_{\mathrm{s}}\left(\mathrm{dl} \mathrm{g}^{-1}\right)$ & $0.27 \pm 0.01^{\mathrm{cd}}$ & $0.18 \pm 0.00^{\mathrm{f}}$ & $0.15 \pm 0.00^{\mathrm{g}}$ \\
\hline 5 & $v(-)$ & $2.48 \pm 0.05^{\mathrm{a}}$ & $2.41 \pm 0.01^{\mathrm{a}}$ & $2.45 \pm 0.00^{\mathrm{a}}$ \\
\hline & $v_{\mathrm{s}}\left(\mathrm{dl} \mathrm{g}^{-1}\right)$ & $0.26 \pm 0.02^{\mathrm{cd}}$ & $0.21 \pm 0.00^{\mathrm{e}}$ & $0.19 \pm 0.00^{\mathrm{f}}$ \\
\hline 10 & $v(-)$ & $2.37 \pm 0.01^{\mathrm{a}}$ & $2.40 \pm 0.01^{\mathrm{a}}$ & $2.43 \pm 0.02^{\mathrm{a}}$ \\
\hline & $v_{\mathrm{s}}\left(\mathrm{dl} \mathrm{g}^{-1}\right)$ & $0.30 \pm 0.00^{\mathrm{b}}$ & $0.29 \pm 0.00^{\mathrm{bc}}$ & $0.26 \pm 0.00^{\mathrm{d}}$ \\
\hline 15 & $v(-)$ & $2.33 \pm 0.02^{\mathrm{a}}$ & $2.34 \pm 0.01^{\mathrm{a}}$ & $2.40 \pm 0.02^{\mathrm{a}}$ \\
\hline & $v_{\mathrm{s}}\left(\mathrm{dl} \mathrm{\textrm {g } ^ { - 1 } )}\right.$ & $0.326 \pm 0.002^{\mathrm{a}}$ & $0.28 \pm 0.00^{\mathrm{bc}}$ & $0.27 \pm 0.00^{\mathrm{cd}}$
\end{tabular}

All data are expressed as mean \pm standard deviation of three determinations. The same letters indicate no significant effect according to the Tukey test $(\mathrm{p}<0.05)$.

The swollen specific volume $\left(v_{s}\right)$, defined as the macromolecular volume in solution per unit anhydrous mass of macromolecule, is an indicator of solvent integration with macromolecule [31]. The values of the $v_{\mathrm{s}}$ of the samples are shown in Table 5. It can be seen that the $v_{\mathrm{s}}$ value of NWS was significantly affected by the CSG substitution. With increasing the substitution level of CSG from 0 to $15 \%$, the $v_{s}$ of NWS increased from $0.27 \mathrm{dl} / \mathrm{g}$ to 0.33 $\mathrm{dl} / \mathrm{g}$. This observation can be related to the solvent's optimal interaction with CSG macromolecules, which increased the $v_{s}$ of the NWS-CSG mixture. By raising the substitution level of SUC from $0 \%$ to $10 \%$, the $v_{\text {s }}$ of NWS decreased significantly from $0.27 \mathrm{dl} / \mathrm{g}$ to 0.15 $\mathrm{dl} / \mathrm{g}$. This observation can be due to a decrease in coil dimensions of NWS or a reduction in the quality of the solvent in the presence of SUC [35]. SUC can decrease the quality of the solvent, thus reduces the dissolution of the NWS molecules and decreases the dimensions of the NWS coil in solution, and consequently decreases the $v_{s}$ and [ $\eta$ ] viscosity of NWS solution [21]. On the other hand, SUC reduces the solvent's interaction with NWS macromolecules because of the competition between SUC and NWS for accessing the solvent. So it decreases the power of swelling and reduces the hydrodynamic volume [10]. Additionally, the intermolecular interaction of starch chains and their aggregation can be caused by decreasing the interaction between starch chains and solvent molecules [28]. Similar observations have been obtained by Heydari et al. [10] and Mohammad Amini and Razavi [28], who reported the swollen specific volumes of NWS and BSG, respectively, decreased by the addition of SUC.

The $v_{s}$ values of the NWS-CSG-SUC mixture at selected substitution levels of the CSG and SUC were in the range of $0.21-0.27 \mathrm{dl} / \mathrm{g}$, which was lower than the $v_{\mathrm{s}}$ values of the NWSCSG mixture and higher than that of the NWS-SUC mixture. However, $10 \%$ and $15 \%$ CSG$5 \%$ SUC mixtures had higher $v_{s}$ values than NWS. It confirmed again that CSG limited the function of SUC on the reduction of the molecular parameters of NWS.

\section{Conclusions}

In this study, the effects of cress seed gum (CSG) and sucrose (SUC) substitution levels on the dilute solution properties of native wheat starch (NWS) were investigated. CSG increased the intrinsic viscosity ([ๆ]) of NWS solution, reduced the NWS Huggins constant $(\mathrm{kH})$, and altered the conformation of NWS from the random coil to the semi-rigid, indicating more polymer-solvent interactions and more expansion of molecular conformation occurred. On the other hand, SUC decreased the $[\eta]$ and increased the $\mathrm{k}_{\mathrm{H}}$ of NWS by changing the solvent 
properties and lesser polymer-solvent interactions. In the presence of SUC, the conformation of starch molecules was less expanded, the intermolecular aggregation increased, and the hydrodynamic volume of NWS molecules reduced. NWS-CSG-SUC mixture had a similar value of $[\eta]$ to the NWS. Its kH value was lower than the NWS, especially at the highest substitution level of CSG, indicating NWS-CSG-SUC mixture had more polymer-solvent interactions. The conformation of the NWS-CSG-SUC mixture was between the random coil and rod-like. Additionally, the results showed that some dilute solution properties in the NWSCSG-SUC mixture, such as [ $\eta], \mathrm{kH}_{\mathrm{H}}$, and molecular conformation, were better than the NWSSUC mixture, especially at the highest level of CSG. It can be concluded that CSG overcame the weakening effect of SUC on the NWS solution properties in the ternary system. The present work observations can be used to improve the rheological and functional properties of formulated systems containing NWS and SUC in different industries.

\section{Funding}

This project was funded by the Deputy of Research, the Ferdowsi University of Mashhad, Iran (Grant No. 47118), and the Iran National Science Foundation (INSF), Iran (Grant No., 96015540). The financial supports are gratefully acknowledged.

\section{Acknowledgments}

This research has no acknowledgment.

\section{Conflicts of Interest}

The authors declare no conflict of interest.

\section{References}

1. Maningat, C.C.; Seib, P.A.; Bassi, S.D.; Woo, K.S.; Lasater, G.D. Wheat Starch: Production, Properties, Modification and Uses. 3rd ed.; Academic Press: San Diego; 2009; pp. 441-510, https://doi.org/10.1016/B978-0-12-746275-2.00010-0.

2. Chibuogwu, C.; Amadi, B.; Anyaegbunam, Z.; Emesiani, B.; Ofoefule, S. Application of Starch and Starch Derivatives in Pharmaceutical Formulation. In: Chemical Properties of Starch. Emeje, M. Ed.; 2019, https://doi.org/10.5772/intechopen.88273.

3. Kunle, O.O. Starch Source and Its Impact on Pharmaceutical Applications. In: Chemical Properties of Starch. Emeje, M. Ed.; 2019; https://doi.org/10.5772/intechopen.89811.

4. Mason, W.R. Starch Use in Foods. In: Starch. 3rd ed.; BeMiller, J.; Whistler, R. Eds.; Academic Press: San Diego, 2009; pp. 745-795, https://doi.org/10.1016/B978-0-12-746275-2.00020-3.

5. Karazhiyan, H.; Razavi, S.MA.; Phillips, G.O.; Fang, Y.; Al-Assaf, S.; Nishinari, K. Rheological properties of Lepidium sativum seed extract as a function of concentration, temperature and time. Food Hydrocoll. 2009, 23, 2062-2068, https://doi.org/10.1016/j.foodhyd.2009.03.019.

6. Behrouzian, F.; Razavi, S.M.A.; Karazhiyan, H. Intrinsic viscosity of cress (Lepidium sativum) seed gum: Effect of salts and sugars. Food Hydrocoll. 2014, 35, 100-105, https://doi.org/10.1016/j.foodhyd.2013.04.019.

7. Karazhiyan, H.; Razavi, S.M.A.; Phillips, G.O.; Fang, Y.; Al-Assaf, S.; Nishinari, K. Physicochemical aspects of hydrocolloid extract from the seeds of Lepidium sativum. Int J Food Sci Technol. 2011, 46, 10661072 .

8. Naji, S.; Razavi, S.M.A.; Karazhiyan, H. Effect of thermal treatments on functional properties of cress seed (Lepidium sativum) and xanthan gums: A comparative study. Food Hydrocoll. 2012, 28, 75-81, https://doi.org/10.1016/j.foodhyd.2011.11.012.

9. Richardson, R.K.; Kasapis, S. Rheological methods in the characterisation of food biopolymers. In: Developments in Food Science. Wetzel, D.L.B.; Charalambous, G. Eds.; Elsevier, Volume 39, 1998; pp. 1-48, https://doi.org/10.1016/S0167-4501(98)80006-X. 
10. Heydari, A.; Razavi, S.M.A.; Irani, M. Effect of temperature and selected sugars on dilute solution properties of two hairless canary seed starches compared with wheat starch. Int J Biol Macromol. 2018, 108, 12071218, https://doi.org/10.1016/j.ijbiomac.2017.11.026.

11. Bak, J.H.; Yoo, B. Intrinsic viscosity of binary gum mixtures with xanthan gum and guar gum: Effect of $\mathrm{NaCl}$, sucrose, and $\mathrm{pH}$. Int $J$ Biol Macromol. 2018, 111, 77-81, https://doi.org/10.1016/j.ijbiomac.2017.12.144.

12. Irani, M.; Razavi, S.M.A.; Abdel-Aal, E-S.M.; Hucl, P.; Patterson, C.A. Dilute solution properties of canary seed (Phalaris canariensis) starch in comparison to wheat starch. Int J Biol Macromol. 2016, 87, 123-129, https://doi.org/10.1016/j.ijbiomac.2016.02.050.

13. Higiro, J.; Herald, T.J.; Alavi, S. Rheological study of xanthan and locust bean gum interaction in dilute solution. Food Res Int. 2006, 39, 165-175, https://doi.org/10.1016/j.foodres.2005.07.011.

14. Khouryieh, H.A.; Herald, T.J.; Aramouni, F.; Alavi, S. Influence of mixing temperature on xanthan conformation and interaction of xanthan-guar gum in dilute aqueous solutions. Food Res Int. 2006, 39, 964973, https://doi.org/10.1016/j.foodres.2006.06.001.

15. Karazhiyan, H.; Razavi, S.M.A.; Phillips, G.O. Extraction optimization of a hydrocolloid extract from cress seed (Lepidium sativum) using response surface methodology. Food Hydrocoll. 2011, 25, 915-920, https://doi.org/10.1016/j.foodhyd.2010.08.022.

16. Huggins, M.L. The Viscosity of Dilute Solutions of Long-Chain Molecules. IV. Dependence on Concentration. J Am Chem Soc. 1942, 64, 2716-2718, https://doi.org/10.1021/ja01263a056.

17. Kraemer, E.O. Molecular Weights of Celluloses and Cellulose Derivates. Ind Eng Chem. 1938, 30, 12001203, https://doi.org/10.1021/ie50346a023.

18. Tanglertpaibul, T.; Rao, M. Intrinsic viscosity of tomato serum as affected by methods of determination and methods of processing concentrates. J Food Sci. 1987, 52, 1642-1645.

19. Lai, L.S.; Tung, J.; Lin, P.S. Solution properties of hsian-tsao (Mesona procumbens Hemsl) leaf gum. Food Hydrocoll. 2000, 14, 287-294, https://doi.org/10.1016/S0268-005X(99)00069-7.

20. Antoniou, E.; Themistou, E.; Sarkar, B.; Tsianou, M.; Alexandridis, P. Structure and dynamics of dextran in binary mixtures of a good and a bad solvent. Colloid Polym Sci. 2010, 288, 1301-1312, https://doi.org/10.1007/s00396-010-2259-x.

21. Morris, E.R.; Cutler, A.N.; Ross-Murphy, S.B.; Rees, D.A.; Price, J. Concentration and shear rate dependence of viscosity in random coil polysaccharide solutions. Carbohydr Polym. 1981, 1, 5-21, https://doi.org/10.1016/0144-8617(81)90011-4.

22. McMillan, D.E. A comparison of five methods for obtaining the intrinsic viscosity of bovine serum albumin. Biopolymers. 1974, 13, 1367-1376.

23. Funami, T.; Kataoka, Y.; Omoto, T.; Goto, Y.; Asai, I.; Nishinari, K. Effects of non-ionic polysaccharides on the gelatinization and retrogradation behavior of wheat starch. Food Hydrocoll. 2005, 19, 1-13, https://doi.org/10.1016/j.foodhyd.2004.04.024.

24. Dokić, P.; Dokić, L.; Dapčević, T.; Krstonošić, V. Colloid Characteristics and Emulsifying Properties of OSA Starches. Springer: Berlin, Heidelberg, 2008; pp 48-56, http://dx.doi.org/10.1007/2882_2008_116.

25. Perez-Rea, D.; Bergenståhl, B.; Nilsson, L. Development and evaluation of methods for starch dissolution using asymmetrical flow field-flow fractionation. Part II: Dissolution of amylose. Anal Bioanal Chem. 2016, 408, 1399-1412, https://doi.org/10.1007/s00216-015-8894-9.

26. Islam, M.N.; Dos Mohd., A.M.; Bin Mohd. Noor, M.A. Effect of Temperature and Starch Concentration on the Intrinsic Viscosity and Critical Concentration of Sago Starch (Metroxylon sagu). Starch - Stärke. 2001, 53, 90-94, https://doi.org/10.1002/1521-379X(200102)53:2<90::AID-STAR90>3.0.CO;2-8.

27. Masselot, V,; Benkhelifa, H.; Cuvelier, G.; Bosc, V. Rheological properties of stabilizers at low temperatures in concentrated sucrose solutions. Food Hydrocoll. 2020, 103, 105691, https://doi.org/10.1016/j.foodhyd.2020.105691.

28. Mohammad Amini, A.; Razavi, S.MA. Dilute solution properties of Balangu (Lallemantia royleana) seed gum: Effect of temperature, salt, and sugar. Int $J$ Biol Macromol. 2012, 51, 235-243, https://doi.org/10.1016/j.ijbiomac.2012.05.018.

29. Millard, M.M.; Dintzis, F.R.; Willett, J.L.; Klavons, J.A. Light-Scattering Molecular Weights and Intrinsic Viscosities of Processed Waxy Maize Starches in 90\% Dimethyl Sulfoxide and H2O. Cereal Chem. 1997, 74, 687-691, https://doi.org/10.1094/cchem.1997.74.5.687.

30. Pamies, R.; Cifre, J.G.H.; Martínez, M.d.C.L,; de la Torre, J.G. Determination of intrinsic viscosities of macromolecules and nanoparticles. Comparison of single-point and dilution procedures. Colloid Polym Sci. 2008, 286, 1223-1231, https://doi.org/10.1007/s00396-008-1902-2.

31. Harding, S.E. Dilute solution viscometry of food biopolymers. In: Functional properties of food macromolecules. 2nd ed.; Hill, S.E.; Ledward, D.A.; Mitchell, J.R. Eds; An Aspen Publication: Gaithersburg, Maryland, Volume 149, 1998.

32. Wang, F.; Sun, Z.; Wang, Y.J. Study of xanthan gum/waxy corn starch interaction in solution by viscometry. Food Hydrocoll. 2001, 15, 575-581, https://doi.org/10.1016/S0268-005X(01)00065-0. 
33. Higiro, J.; Herald, T.; Alavi, S.; Bean, S. Rheological study of xanthan and locust bean gum interaction in dilute solution: Effect of salt. Food Res Int. 2007, 40, 435-447, https://doi.org/10.1016/j.foodres.2006.02.002.

34. Joseph, R.; Devi, S.; Rakshit, A.K. Viscosity behaviour of acrylonitrile-acrylate copolymer solutions in dimethyl formamide. Polym Int. 1991, 26, 89-92, https://doi.org/10.1002/pi.4990260206.

35. Razavi, S.M.A.; Moghaddam, T.M.; Emadzadeh, B.; Salehi, F. Dilute solution properties of wild sage (Salvia macrosiphon) seed gum. Food Hydrocoll. 2012, 29, 205-210, https://doi.org/10.1016/j.foodhyd.2012.02.020. 